findings suggest future research on EC access and possible expansion of STI screening programs into real world settings, such as pharmacies.

Abstract P2-S9.03 Table 1 Prevalence of lifetime emergency contraception (EC) use

\begin{tabular}{|c|c|c|c|}
\hline & $\mathbf{n}$ & (\%) SE & $\begin{array}{l}\text { Population total } \\
\text { (weighted } \mathrm{n} \text { ) }\end{array}$ \\
\hline \multicolumn{4}{|l|}{ Ever used EC ( $n=6326)$} \\
\hline Yes & 704 & (9.7) 0.9 & $5,1171,887$ \\
\hline No & 5623 & (90.2) 0.9 & $48,055,234$ \\
\hline \multicolumn{4}{|l|}{ Used EC in past 12 months $(n=6327)$} \\
\hline Yes & 175 & (2.1) 0.3 & $1,156,443$ \\
\hline No & 6151 & (97.8) 0.9 & $52,068,403$ \\
\hline \multicolumn{4}{|l|}{ No of times ever used ( $n=703$ ) } \\
\hline 1 & 431 & (61.9) 3.6 & $3,180,161$ \\
\hline 2 & 160 & (24.3) 2.4 & $1,248,453$ \\
\hline $3+$ & 112 & (13.8) 3.0 & 709,209 \\
\hline \multicolumn{4}{|l|}{ Primary reasons for $\mathrm{EC}$ use ${ }^{*}(\mathrm{n}=703)$} \\
\hline $\begin{array}{l}\text { Worried birth control method would not } \\
\text { work }\end{array}$ & 271 & (42.3) 4.3 & $2,188,726$ \\
\hline Didn't use birth control that time & 345 & (45.8) 3.5 & $2,369,367$ \\
\hline Other reason & 87 & (11.8) 1.3 & 610,641 \\
\hline \multicolumn{4}{|l|}{ Where received EC $(n=449)$} \\
\hline Private doctors/HMO & 74 & (16.5) 1.2 & 905,108 \\
\hline $\begin{array}{l}\text { Community Clinic/FP clinic/school-based } \\
\text { Clinic }\end{array}$ & 232 & $(50.8) 4.3$ & $2,228,311$ \\
\hline Hospital facility or urgent care & 29 & (6.2) 1.1 & 342,076 \\
\hline Friend, partner, or spouse & 13 & (2.3) 0.6 & 123,784 \\
\hline Drug store & 95 & (23.1) 2.5 & $1,266,920$ \\
\hline Other place & 6 & (1.0) 0.2 & 57,439 \\
\hline \multicolumn{4}{|l|}{ Obtained EC with a $R x(n=144)$} \\
\hline Yes & 49 & (31.4) 2.3 & 764,194 \\
\hline No & 95 & (68.6) 2.3 & $1,645,951$ \\
\hline
\end{tabular}

*First reason mentioned for the last (or only) time used EC.

†Population totals reflect US women age 15-44 years.

\section{P2-S9.04 CONDOM NON-USE IS ASSOCIATED WITH LOW PERCEPTION OF RISK FOR STIS IN YOUNG SEXUALLY ACTIVE WOMEN}

doi:10.1136/sextrans-2011-050108.390

C Boyer, L Pollack, M A Shafer. University of California, San Francisco, USA

Background Research indicates perception of risk is necessary for adoption of health protective behaviour. Many studies report optimistic bias in risk perceptions, ie, actual risk exceeds perceived risk. This study assessed the relationship between sexual risk behaviours and perceived risk for acquisition of an STI in a cohort of sexually experienced young women.

Methods Female Marine Corps recruits volunteered to participate in a cognitive-behavioural intervention to decrease STIs and unintended pregnancies that took place during Recruit Training (RT). Data are from the follow-up questionnaire (median=9.8 months post RT) for women who reported vaginal/anal sex since RT $(\mathrm{N}=1192)$. Perceived risk was assessed by, I think my chance of getting an STI during my next 6 months in the Corps is about." ( $0 \%$, $1 \%, 5 \%$, then $10 \%-100 \%$ in $10 \%$ jumps). Sexual risk behaviours since completing RT included \# sex partners (1/2/3/4/5+), \# casual partners $(0 / 1 / 2 / 3+)$, \% of time used condoms during sex (100/ 90-99/60-80/50/10-40/0), frequency of sex after drinking alcohol/ using drugs (never/almost never/sometimes/usually or always), and whether any partner had an STI or was having sex with others (no/possible/yes). Bivariate relationships between sexual risk behaviour and perceived risk were evaluated using negative binomial regression.
Results Perceived risk was low (mean=6.05). All risk behaviours were significantly associated with perceived risk $(p<0.001)$. In general, perceived risk increased as behavioural risk increased except for condom use. Pairwise comparisons show the $0 \%$ group mean (2.41) is higher than for the $100 \%$ group $(1.47, p<0.05)$, but lower than the $90-99 \%$ group $(3.96, p<0.05)$, and much lower than the $60-80 \%, 50 \%$, and $10-40 \%$ groups $(9.03,8.88$, and 11.05 respectively; all $\mathrm{p}<0.001)$. Restricting the analysis to participants with multiple partners or to unmarried women yielded the same results. Associations between sexual risk behaviour and two other measures of perceived risk (own risk relative to other female Marines, risk of behaviour for getting an STI; not shown) parallel the results described here.

Conclusions There is a major disconnect between women's perception of risk and their condom use, the most effective means for preventing common STIs. Since women must negotiate with and rely on male sexual partner(s) for condom use, future research should further examine social and contextual factors that influence young women's perceptions of risk in relation to condom use.

\section{P2-S9.05 OUALITATIVE ASSESSIMENT OF ANAL INTERCOURSE AND RECTAL LUBRICANT USE AMONG WOMEN IN LOS ANGELES}

doi:10.1136/sextrans-2011-050108.391

${ }^{1} \mathrm{M}$ Javanbakht, ${ }^{1} \mathrm{~J}$ Brown, 'B Amani, ${ }^{1} \mathrm{~S}$ Stahlman, ${ }^{1} \mathrm{P}$ Gorbach, ${ }^{2} \mathrm{~S}$ Brown, ${ }^{2} \mathrm{C}$ Murphy, ${ }^{2} \mathrm{M}$ Hezareh. ${ }^{1}$ University of California, Los Angeles, USA; ${ }^{2}$ AIDS Research Alliance USA

Background There is increasing evidence that anal intercourse (AI) is a relatively common sexual practice among women. Although AI has a high probability of transmission of STIs/HIV, circumstances surrounding $\mathrm{AI}$ and the potential risk context among women are not well understood.

Methods Between May and August 2008, we recruited 30 racially and ethnically diverse women (10 African American, 10 Latina, and 10 White) age 18 years and older through community outreach efforts in Los Angeles, CA. Women underwent an in-depth interview that examined their intravaginal and anal practices. In this analysis we focus on identifying differing contextual meanings associated with AI through emergent themes and explore differences in these themes by race/ethnicity.

Results The majority of women reported experience with anal intercourse with a substantial number reporting recent experience with AI (ie, in the past year). While there were discussions of AI from women describing casual or transactional sexual partnerships, most women reported $\mathrm{AI}$ in the context of serious relationships. AI had varied meanings for women such as an expression of deeper intimacy, a representation of partner's pleasure, and a method for increased sexual gratification. In terms of what AI means in relation to other sexual acts, very few women reported having only AI and in fact it was considered going all out" and generally followed oral and vaginal sex. It is unclear if the women associated STI risk with AI practices since consistent condom use with AI was rare and those who reported condom use noted it as a strategy to improve "cleanliness" (unrelated to STIs) and reduce discomfort so that AI was "not so rough." Lubricant use for AI, including saliva, petroleum jelly, and baby oil was common and at least one woman specifically reported on the use of "spermicide jelly." Each of the race/ethnic groups provided support for the themes identified suggesting that the groups may not differ much regarding some of the contextual factors surrounding anal intercourse.

Conclusions These findings highlight that AI is common among women, particularly among those in serious relationships suggesting a need to reframe AI as not just risk behaviour but as a sexual health issue. While condom use with AI is not common, the use of anal 
lubricating products not specifically designed for intercourse is common. The frequency and potential health effects of AI lubricants warrant further study.

\section{P2-S9.06 VAGINAL FILM MICROBICIDES FOR HIV PREVENTION: A MIXED METHODS STUDY OF WOMEN'S PREFERENCES}

doi:10.1136/sextrans-2011-050108.392

${ }^{1} \mathrm{M}$ Fan, 'L Ferguson, 'L Rohan, ${ }^{2} \mathrm{~L}$ Meyn, ${ }^{1} \mathrm{~S}$ Hillier. ${ }^{1}$ University of Pittsburgh, Pittsburgh, USA; ${ }^{2}$ Magee-Womens Research Institute, Pittsburgh, USA

Background Quick-dissolve films hold promise for HIV microbicide formulation with regards to low cost and scalable manufacture. Consideration of women's preferences enhances probable use of promising microbicides. This study examined preferred physical characteristics of quick-dissolve vaginal films for HIV prevention and factors that influenced valuation of HIV prevention.

Methods We conducted a cross-sectional mixed methods study of women aged 18-30 years from two counties in southwestern Pennsylvania to qualitatively and quantitatively assess preferences. During focus groups women handled and evaluated films of varying texture, thickness, size, shape, and appearance. A prefocus group survey collected demographics, sexual history, and valuation of vaginal product characteristics. A post-focus group survey collected attitudes towards vaginal microbicides. We carried out thematic analysis of focus group transcripts using modified grounded theory. We examined relationships between participant characteristics and valuing HIV prevention using Fisher's exact test.

Results Eighty-four women participated, with a mean age of 23 years and largely white (54\%) and black (43\%). Only three reported previous use of a vaginal film. Participants preferred films to be smooth and thin (63\%), translucent (48\%), and $2 \times 2$ " square size $(36 \%)$. Translucent and smooth, thin films were perceived as likely to disintegrate rapidly. Smooth, thin films were perceived as more comfortable and less irritating than textured, thick films. Translucent films were thought to represent a balance between discretion and visual discernibility. Easy, accurate insertion, uniform coverage, and adequate HIV prevention efficacy were viewed as advantages of $2 " \times 2$ " square size films. Engaging in at least one episode of binge drinking in the past year was associated with rating HIV prevention as important $(p=0.048)$. Participants expressed concern regarding sexual intercourse in the context of alcohol intoxication. Factors associated with ranking HIV prevention as the most important characteristic of a vaginal product included higher number of lifetime vaginal sex partners $(p=0.001)$ and black race $(\mathrm{p}=0.011)$

Conclusions Smooth, thin, translucent, and 2" $\times 2$ " square films were perceived to offer features valued by women in our sample. Women were concerned with issues of use, including insertion, disintegration, and comfort, as well as issues of discretion and efficacy.

\section{P2-S9.07 ECONOMIC RISK FACTORS FOR SYPHILIS INFECTION AMONG PREGNANT WOMEN IN RURAL HAITI}

\section{doi:10.1136/sextrans-2011-050108.393}

${ }^{1} \mathrm{~J}$ Mark, ${ }^{2} \mathrm{~L}$ Wesler, ${ }^{3} \mathrm{C}$ Oswald, ${ }^{2} \mathrm{~F}$ Léandre, ${ }^{2} \mathrm{P}$ Nevil, ${ }^{2} \mathrm{D}$ Bertrand, ${ }^{2} \mathrm{~J}$ Bertrand, ${ }^{3} \mathrm{~F}$ Boehm, ${ }^{3,4} \mathrm{M}$ C Smith Fawzi. ${ }^{1}$ Centers for Disease Control and Prevention Atlanta, USA; ${ }^{2}$ Zanmi Lasante Sociomedical Complex Cange, Haiti; ${ }^{3}$ Partners In Health Boston, USA; ${ }^{4}$ Harvard Medical School, Boston, USA

Background Of the 12 million global adult syphilis infections occurring globally each year, syphilis disproportionately affects women in low-income countries. WHO estimates about $80 \%$ of syphilis positive pregnancies go untreated, often in Latin America and Africa. Economic and socio-structural characteristics may explain some of the vulnerability for infection. We studied the association between social and health services factors and syphilis in Haiti, a poor country with a high burden of infection.

Methods We used data collected for a clinic-based case-control study of pregnant women attending general care women's clinics in rural Haiti from June 1999-to March 2001. Syphilis serostatus was determined by RPR test. Women were surveyed on socio-demographic and economic factors, access to healthcare, and sexual and gynaecological history. We performed multivariate analysis in SAS to identify factors associated with syphilis seropositivity and present results on two models.

Results The 596 women studied were typically young, rural, and lived in poverty. Syphilis and HIV seropositivity were $5.5 \%$ and $4.3 \%$, respectively. In model $1(n=396)$, factors associated with maternal syphilis infection were: household monthly per capita income $<75$ goud (\$20 USD) (OR 2.4, 95\% CI 0.9 to 6.6), having a 1 room house (OR 5.2, 95\% CI 1.6 to 17.0 ), and history of prior pregnancy resulting in premature birth (OR 5.1, 95\% CI 2.0 to 13.0) In model $2(n=417)$, having fields where family members plant crops was a protective factor (OR $0.26,95 \%$ CI 0.074 to 0.92 ), while reporting problems obtaining education (OR 3.2, 95\% CI 1.1 to 7.7 ), $<15$ years of age at first intercourse (OR 2.9, 95\% CI 1.1 to 7.7 ), history of an STD (OR=11.0, 95\% CI 3.2 to 40.0), and vaginal discharge with odour (OR 3.4, 95\% CI 1.1 to 11.0) were associated with maternal syphilis infection see Abstract P2-S9.07 Table 1.

Discussion Among pregnant women in Haiti, some economic characteristics were predictors of vulnerability for syphilis infection and may help explain the inequitable distribution of syphilis disease burden. Further study is warranted to understand specific economic or other structural factors that may affect syphilis infection in women and may be amenable to intervention.

Abstract P2-S9.07 Table 1 Multiple logistic regression analysis of factors associated with maternal syphilis status of women in rural Haiti

\begin{tabular}{|c|c|}
\hline & OR $(95 \% \mathrm{CI})$ \\
\hline \multicolumn{2}{|l|}{ Model $1(n=396)$} \\
\hline Monthly per capita income less than 75 goud/person & $2.4(0.9$ to 6.5$)$ \\
\hline House has 1 room only & $5.2(1.6$ to 17.0$)$ \\
\hline$\leq 15$ years old at first sexual intercourse & $1.8(0.7$ to 4.5$)$ \\
\hline History of premature birth & $5.1(2.0$ to 13.0$)$ \\
\hline \multicolumn{2}{|l|}{ Model $2(n=417)$} \\
\hline Has fields where family members plant crops & $0.26(0.1$ to 0.9$)$ \\
\hline House has 1 room only & $1.6(0.4$ to 6.3$)$ \\
\hline Has problems with education & $3.2(1.1$ to 9.3$)$ \\
\hline$\leq 15$ years old at first sexual intercourse & $2.9(1.1$ to 7.7$)$ \\
\hline More than 1 lifetime sexual partner & $1.1(0.4$ to 3.2$)$ \\
\hline $\begin{array}{l}\text { Had sexual intercourse with someone she knows or } \\
\text { suspects had an STD }\end{array}$ & $2.9(0.3$ to 30.0$)$ \\
\hline History of an STD & 11 (3.2 to 40.0$)$ \\
\hline Vaginal discharge with a bad smell & $3.4(1.1$ to 11.0$)$ \\
\hline Travels to clinic or health center by bus & $1.8(0.6$ to 5.3$)$ \\
\hline $\begin{array}{l}\text { Has more difficulties getting to usual health center or } \\
\text { clinic during rainy season compared to dry season }\end{array}$ & $0.4(0.2$ to 1.2$)$ \\
\hline
\end{tabular}

\section{P2-S9.08 BABY DADDY SEX AS A RISK FACTOR FOR HIV/STDS}

doi:10.1136/sextrans-2011-050108.394

P Padgett, J Risser. University of Texas School of Public Health, Houston, USA

Background Concurrent sexual relationships increase the likelihood of exposure to HIV/STDs. Sexual patterns among poor urban 